\title{
Clinical profile and outcomes of asymptomatic vs. symptomatic travellers diagnosed with COVID-19: An observational study from a coastal town in South India
}

\author{
Nitin Gupta ${ }^{1,4}$, Anupa John², Mohammed Safeer Kokkottil ${ }^{1}$, Muralidhar Varma ${ }^{1}$, \\ Shashikiran Umakanth ${ }^{3}$, Kavitha Saravu, ${ }^{1,4}$, \\ ${ }^{1}$ Department of Infectious Diseases, Kasturba Medical College, Manipal Academy of Higher Education, Manipal, Karnataka, India; \\ ${ }^{2}$ Department of Medicine, Kasturba Medical College, Manipal Academy of Higher Education, Manipal, Karnataka, India; \\ ${ }^{3}$ Department of Medicine, Dr TMA Pai Hospital, Melaka Manipal Medical College, Manipal Academy of Higher Education, Manipal, Karnataka, \\ India; \\ ${ }^{4}$ Manipal Center for Infectious Diseases, Prasanna School of Public Health, Manipal Academy of Higher Education, Manipal, Karnataka, India.
}

SUMMARY Despite the high number of coronavirus disease-19 (COVID-19) cases from India, there are few reports from India describing the clinical epidemiology of COVID-19. This study aimed to describe the clinical/epidemiological characteristics and outcomes of asymptomatic vs. symptomatic COVID-19 patients. This was a retrospective chart review of all admitted patients with COVID-19 above 18 years with a history of travel within one month of the admission. The patients were categorized into asymptomatic and symptomatic. The symptomatic patients were further classified into mild, moderate and severe. The demographic profile, risk factors, clinical features, laboratory parameters, treatment details and outcome of all patients were recorded. The clinical and laboratory parameters were compared between symptomatic patients and asymptomatic patients. Of the 127 recruited patients, 75 were asymptomatic. Of the 52 symptomatic patients, 41 patients were classified as a mild illness. The mean age of the patients was $44.5 \pm 15$ years. A total of 73 patients had one or more risk factors. The male patients were more commonly found to be symptomatic compared to female patients. Neutrophil-lymphocyte ratio, C-reactive protein and lactate dehydrogenase were significantly elevated in symptomatic patients. A total of five individuals required supplemental oxygen therapy, and one of them required mechanical ventilation. All the patients had favourable outcomes. Asymptomatic and mild illness form a significant proportion of positive patients and have excellent outcomes without therapeutic interventions.

Keywords Pregnancy, household contact, COVID-19, Presymptomatic, asymptomatic, transmission, SARSCoV-2

\section{Introduction}

Severe acute respiratory syndrome-coronavirus-2 (SARS-CoV-2), the causative agent of coronavirus disease-19 (COVID-19) is peculiar in terms of transmission dynamics and clinical manifestations despite its genetic relatedness to other coronaviruses (1). The virus multiplies in the upper respiratory tract, and the peak viral load is reached even before the symptom onset. As a result, asymptomatic individuals can also transmit. In those who are symptomatic, the manifestations range from mild to severe, requiring intensive care. Studies have shown that the proportion of asymptomatic and mild illness is significantly higher and a tiny proportion of individuals develop a severe disease (2-4). Therefore, predictive scores based on comorbidities and laboratory parameters have been suggested to identify those individuals that require higher levels of care (5). The treatment for COVID-19 has also been continuously evolving with many of the proposed drugs failing to show benefits in randomized controlled trials (6).

Despite the high number of cases, there are relatively fewer reports from India describing the clinical epidemiology of COVID-19. Most of the reports are from tertiary care hospitals that often underestimate the actual proportion of asymptomatic/mild illness as only symptomatic individuals with more distressing symptoms are predominantly admitted in the hospital. Similar to other parts of the globe, the initial cases in 
India were from the travellers. As per the regulations, testing and hospital-based treatment (irrespective of symptoms) were recommended for all travellers in the early part of the pandemic. It was hypothesized that the study of a cohort of travellers with COVID-19 would represent a distinct cohort. Therefore, this study aimed to describe the clinical-epidemiological characteristics and outcomes of hospitalized COVID-19 patients with travel history.

\section{Materials and Methods}

The study was a retrospective chart review conducted at Dr TMA Pai Hospital, Udupi (dedicated COVID-19 centre under public-private partnership) after taking permission from the Institute's Ethics Committee. The study was registered with the Clinical Trials Registry of India. The clinical case records of all admitted patients above 18 years with COVID-19 (based on realtime reverse-transcriptase polymerase chain reaction assay) between $1^{\text {st }}$ of May, 2020 and $10^{\text {th }}$ of July, 2020 were screened for eligibility. Those with a history of travel (international/national/state) within one month of the admission were included. After recruitment, the data was entered into a pre-defined case record form. The patients will be categorized into following categories: asymptomatic (No symptoms throughout the course), presymptomatic (No symptoms at the time of swab but developed symptoms later) and symptomatic (symptoms at the time of swab). The symptomatic patients were further categorized into mild, moderate and severe (Table 1). All patients were managed according to the institution protocol that was regularly updated. Routine investigations were done in all the patients - complete blood count (CBC), liver function tests (LFT), renal function tests (RFT), $\mathrm{C}$-reactive protein (CRP) and lactate dehydrogenase (LDH). Ferritin and d-dimer were done on a case to case basis. Asymptomatic patients with mild disease were managed conservatively. They were not given any antivirals, steroids or immunomodulators. Those patients with moderate/severe disease were treated with supplemental oxygen therapy, hydroxychloroquine, low molecular weight heparin and steroids. Awake prone positioning was administered in all patients requiring oxygen. Those who did not respond to oxygen therapy were managed with non-invasive ventilation and mechanical ventilation. Two negative swabs were mandatory for discharge as per the state guidelines in the early part of the study period. The following details were recorded: the demographic profile, risk factors for severe disease (age $>60$ years, hypertension, diabetes, chronic kidney disease, chronic lung disease, coronary artery disease, immunosuppression), clinical features, laboratory parameters, Chest X-Ray findings, treatment details and outcome. Based on an online web calculator, the patients were categorized into low $(0.7 \%$ probability), medium (7.3\% probability) and high risk (59.3\% probability) of acquiring critical (mechanical ventilation/intensive care/death) illness (5).

Data analysis: continuous data were presented as either mean with standard deviation (SD) or median with interquartile range (IQR) depending on the data distribution. The frequency of categorical variables was expressed in numbers and percentage. The clinical and laboratory parameters were compared between symptomatic patients and asymptomatic patients. Chisquare test was used for categorical variables, and independent $t$-test was used for quantitative variables. A $p$-value of less than 0.05 was considered significant. All analyses were done using SPSSv26.

\section{Results}

Of the 127 patients, 75 were asymptomatic, and 52 were symptomatic (Table 1). The median duration of illness at admission in the 52 symptomatic patients was 4 (IQR 2.25-6.75) days. The demographic details are summarized in Table 2. The mean age of the patients was 44.5 (SD-15) years. The risk factors for severe disease are summarized in Table 3. A total of 73 patients had one or more risk factors for severity. The median duration from the day of swabbing to admission was 4 (IQR 2-7) days. The clinical features of symptomatic patients are summarized in Table 4 . The median duration of illness from travel to admission was 9 (IQR 6-18) days. The mean pulse rate at presentation was 88.8 (SD-14.3) per minute. The mean respiratory rate at presentation was 18.6 (2.9) per minute. The mean systolic blood pressure (SBP) and diastolic blood pressure (DBP) at presentation were 126.9 (SD-18.5) millimetre $(\mathrm{mm})$ of mercury $(\mathrm{Hg})$ and 81.3 (SD-11.3) $\mathrm{mm}$ of $\mathrm{Hg}$ respectively. The mean saturation $(\mathrm{SpO} 2)$ was $97.8(1.8) \%$. A total of seven patients had Chest $\mathrm{X}$-ray infiltrates (including two patients who were diagnosed with tuberculosis).

Table 1. Breakup of travellers admitted with COVID-19

\begin{tabular}{lcccc}
\hline Staging & Symptoms & Clinical signs of pneumonia & $\begin{array}{l}\text { Oxygen Saturation }\left(\mathrm{SpO}_{2}\right) \& \\
\text { Respiratory rate (RR) cut off }\end{array}$ \\
\hline Asymptomatic & No & No & - & $75(59 \%)$ \\
Mild & Yes & No & RR $<24 / \min$ & $41(36.2 \%)$ \\
Moderate & Yes & Yes & RR 24-30/min or $\mathrm{SpO}_{2} 90-94 \%$ & $2(1.6 \%)$ \\
Severe & Yes & Yes & RR $>30 / \min _{2} \mathrm{SpO}_{2}<90 \%$ & $3(2.4 \%)$ \\
\hline
\end{tabular}


Table 2. Demographic details of the patients

\begin{tabular}{|c|c|c|}
\hline Demographic details & $\begin{array}{c}\text { Frequency } \\
(n=127)\end{array}$ & Percentage \\
\hline \multicolumn{3}{|l|}{ Month of Admission } \\
\hline May & 41 & $32.3 \%$ \\
\hline June & 73 & $57.5 \%$ \\
\hline July (till the $10^{\text {th }}$ of July) & 13 & $10.2 \%$ \\
\hline \multicolumn{3}{|l|}{ Travel } \\
\hline International & 12 & $9.5 \%$ \\
\hline National & 107 & $84.2 \%$ \\
\hline State & 8 & $6.3 \%$ \\
\hline History of contact with a positive patient & 11 & $8.7 \%$ \\
\hline \multicolumn{3}{|l|}{ Age } \\
\hline $18-30$ years & 27 & $21.2 \%$ \\
\hline $31-40$ years & 34 & $26.8 \%$ \\
\hline $41-50$ years & 16 & $12.6 \%$ \\
\hline $51-60$ years & 27 & $21.2 \%$ \\
\hline$>60$ years & 23 & $18.1 \%$ \\
\hline \multicolumn{3}{|l|}{ Occupation } \\
\hline Unemployed & 9 & $7 \%$ \\
\hline Home-maker & 35 & $27.6 \%$ \\
\hline Hotel employee & 22 & $17.3 \%$ \\
\hline Manual labour & 6 & $4.7 \%$ \\
\hline Health care worker & 4 & $3.1 \%$ \\
\hline Student & 4 & $3.1 \%$ \\
\hline Others & 47 & $37 \%$ \\
\hline
\end{tabular}

The laboratory parameters of the admitted patients have been summarized in Table 5. A total of two patients had leucopenia, while five patients had leucocytosis. A total of seven patients had thrombocytopenia. Neutrophil-lymphocyte ratio (NLR) was more than 3 in 31 patients. CRP was elevated $(>5 \mathrm{mg} / \mathrm{L})$ in a total of 46 patients. $\mathrm{LDH}$ was elevated $(>280 \mathrm{U} / \mathrm{L})$ in a total of 46 patients. Bilirubin was elevated $(>1.2 \mathrm{mg} /$ $\mathrm{dL})$ in four patients. Aspartate transaminase (AST) $(>40 \mathrm{U} / \mathrm{L})$ and alanine transaminase (ALT) $(>40 \mathrm{U} /$ L) were elevated in 18 and 21 patients respectively. Alkaline phosphatase (ALP) $(>105 \mathrm{U} / \mathrm{L})$ was elevated in 23 patients. Creatinine was elevated $(>1.2 \mathrm{mg} / \mathrm{dL})$ in five patients. Ferritin was done in 76 patients, and the median ferritin value was 202 (95.4-424.5) nanogram per millilitre. D-dimer was done in 56 patients with a median value of $0.3(0.2-0.48) \mathrm{mcg} / \mathrm{mL}$. D-dimer $(>0.5$ $\mathrm{mcg} / \mathrm{mL}$ ) was elevated in 13 patients.

On comparing the clinical and laboratory manifestations of symptomatic $v s$. asymptomatic patients, male patients were more commonly symptomatic than female patients (Table 6). Platelet count, CRP, LDH, AST and ALT were significantly higher in symptomatic

Table 3. Risk factors in patients diagnosed with COVID-19

\begin{tabular}{|c|c|c|c|c|c|}
\hline \multirow{2}{*}{ Clinical details } & \multicolumn{2}{|c|}{ Total number of patients (127) } & \multicolumn{2}{|c|}{ Total symptomatic (52) } & \multirow{2}{*}{$\begin{array}{c}\text { Moderate/Severe } \\
\text { (5) }\end{array}$} \\
\hline & Frequency & Percentage & Frequency & Percentage & \\
\hline \multicolumn{6}{|l|}{ Number of risk-factors } \\
\hline 0 & 52 & $40.9 \%$ & 24 & $46.1 \%$ & 3 \\
\hline 1 & 39 & $30.7 \%$ & 14 & $26.9 \%$ & 2 \\
\hline 2 & 19 & $15 \%$ & 7 & $1.9 \%$ & 0 \\
\hline More than equal to 3 & 17 & $13.4 \%$ & 7 & $1.9 \%$ & 0 \\
\hline \multicolumn{6}{|l|}{ Risk factors } \\
\hline Age $>60$ years & 23 & $18.1 \%$ & 9 & $17.3 \%$ & 1 \\
\hline Hypertension & 40 & $31.5 \%$ & 17 & $32.7 \%$ & 1 \\
\hline Diabetes mellitus & 39 & $30.7 \%$ & 16 & $30.8 \%$ & 1 \\
\hline Pregnancy & 14 & $11 \%$ & 2 & $3.8 \%$ & 0 \\
\hline Coronary artery disease & 6 & $4.7 \%$ & 2 & $3.8 \%$ & 0 \\
\hline Chronic lung disease & 4 & $3.1 \%$ & 4 & $7.7 \%$ & 0 \\
\hline Human immunodeficiency virus infection & 2 & $1.6 \%$ & 0 & $0 \%$ & 0 \\
\hline
\end{tabular}

Table 4. Clinical features of patients with COVID-19

\begin{tabular}{|c|c|c|c|}
\hline Clinical details & Frequency & Percentage of total $(n=127)$ & Percentage of symptomatic $(n=52)$ \\
\hline Fever & 19 & $15 \%$ & $36.5 \%$ \\
\hline Cough & 30 & $23.6 \%$ & $57.7 \%$ \\
\hline Sore throat & 9 & $7 \%$ & $17.3 \%$ \\
\hline Rhinitis & 6 & $4.7 \%$ & $11.5 \%$ \\
\hline Dyspnoea & 6 & $4.7 \%$ & $11.5 \%$ \\
\hline Headache & 3 & $2.4 \%$ & $5.8 \%$ \\
\hline Myalgia & 2 & $1.6 \%$ & $3.8 \%$ \\
\hline Loss of taste & 3 & $2.4 \%$ & $5.8 \%$ \\
\hline Loss of smell & 1 & $0.8 \%$ & $1.9 \%$ \\
\hline Chest discomfort & 1 & $0.8 \%$ & $1.9 \%$ \\
\hline Tachycardia (> 100 per minute) & 25 & $19.7 \%$ & $48 \%$ \\
\hline Bradycardia $(<60$ per minute $)$ & 3 & $2.4 \%$ & $5.8 \%$ \\
\hline Tachypnoea ( $>20$ per minute) & 31 & $2.4 \%$ & $59.6 \%$ \\
\hline Hypotension & 0 & $0 \%$ & $0 \%$ \\
\hline Hypoxia $(<94 \%)$ & 5 & $3.9 \%$ & $9.6 \%$ \\
\hline
\end{tabular}


Table 5. Laboratory parameters of patients diagnosed with COVID-19

\begin{tabular}{|c|c|c|c|}
\hline Laboratory parameters & Mean (Standard deviation) & Median (Inter Quartile range) & Reference range \\
\hline Total leucocyte count (/mcL) & $7,300(2300)$ & & $4,000-11,000$ \\
\hline Neutrophil-lymphocyte ratio & & $2.3(1.7-3.8)$ & $1-3$ \\
\hline Platelet count at admission (lakhs/mcL) & $2.98(1.08)$ & & $1.5-4$ \\
\hline C-reactive protein $(\mathrm{mg} / \mathrm{L})$ & & $3(1-10.5)$ & $0-5$ \\
\hline Lactate dehydrogenase(U/L) & $283.4(106.4)$ & & $125-220$ \\
\hline Bilirubin (mg/dL) & & $0.5(0.3-0.6)$ & $0.3-1.2$ \\
\hline Aspartate transaminase $(\mathrm{U} / \mathrm{L})$ & & $23(18-30.7)$ & $0-40$ \\
\hline Alanine transaminase $(\mathrm{U} / \mathrm{L})$ & & $22(16-32)$ & $0-40$ \\
\hline Alkaline phosphatase (U/L) & $83.6(25)$ & & $35-105$ \\
\hline Creatinine (mg/dL) & $0.81(0.23)$ & & $0.7-1.2$ \\
\hline
\end{tabular}

Table 6. Asymptomatic vs. symptomatic COVID-19

\begin{tabular}{|c|c|c|c|}
\hline Parameters & Asymptomatic $(n=75)$ & Symptomatic $(n=52)$ & $p$-value \\
\hline Sex & & & 0.004 \\
\hline Male $(n=84), \%$ & $42(50 \%)$ & $42(50 \%)$ & \\
\hline Female $(n=43), \%$ & $33(77 \%)$ & $10(23.2 \%)$ & \\
\hline Number of comorbidities, $n(\%)$ & & & 0.589 \\
\hline $0(n=52), \%$ & $28(53.8 \%)$ & $24(46.1 \%)$ & \\
\hline $1(n=39), \%$ & $25(64.1 \%)$ & $14(35.9 \%)$ & \\
\hline$>1(n=36), \%$ & $22(61.1 \%)$ & $14(38.9 \%)$ & \\
\hline Hypertension, $n(\%)(n=40), \%$ & $23(57.5 \%)$ & $17(42.5 \%)$ & 0.809 \\
\hline Angiotensin receptor blocker $(n=15), \%$ & $9(60 \%)$ & $6(40 \%)$ & 0.937 \\
\hline Diabetes $(n=39), \%$ & $23(59 \%)$ & $16(41 \%)$ & 0.990 \\
\hline Pregnancy $(n=14), \%$ & $12(85.7 \%)$ & $2(14.3 \%)$ & 0.03 \\
\hline Age $>60$ years $(n=23), \%$ & $14(60.9 \%)$ & $9(39.1 \%)$ & 0.84 \\
\hline Mean total leucocyte count in /mcL (Standard deviation) & $7460(2243)$ & $6973(2294)$ & 0.877 \\
\hline Median neutrophil lymphocyte ratio (Inter-quartile range) & $2.3(1.7-3.6)$ & $2.4(1.7-3.8)$ & 0.850 \\
\hline Mean platelet in lakhs/mcL (Standard deviation) & $2.8(1.6)$ & $3.2(1.2)$ & 0.04 \\
\hline Median C-reactive protein in mg/L (Inter-quartile range) & $2(1-5)$ & $7(1.2-51.2)$ & 0.001 \\
\hline Mean Lactate dehydrogenase in U/L (Standard deviation) & $253(67)$ & $315(138)$ & $<0.001$ \\
\hline Median Aspartate transaminase in U/L (Inter-quartile range) & $21(16-25)$ & $27.5(20.2-44)$ & $<0.001$ \\
\hline Median Alanine transaminase in U/L (Inter-quartile range) & $18(14-27)$ & $28(20.2-48.7)$ & 0.001 \\
\hline Mean Alkaline phosphatase in U/L (Standard deviation) & $82.8(24)$ & $83.9(26.3)$ & 0.813 \\
\hline Mean Bilirubin in mg/dL (Standard deviation) & $0.5(0.2)$ & $0.6(0.3)$ & 0.109 \\
\hline Mean Creatinine in mg/dL (Standard deviation) & $0.8(0.2)$ & $0.9(0.2)$ & 0.384 \\
\hline
\end{tabular}

patients than asymptomatic patients (Table 6).

A total of five individuals required oxygen. The day of oxygen requirement from the day of onset of illness ranged from 6-10 days. Two of these patients developed acute respiratory distress syndrome (ARDS) in the disease course, and one of them required mechanical ventilation. The risk of developing critical illness according to the COVID GRAM calculator was as follows: low $(n=61)$, moderate $(n=63)$ and high risk $(n=3)$. Of the five patients who eventually required oxygen, three were categorized as high risk while the other two were classified as moderate risk (5).

A total of 15 hypertensive patients were on angiotensin receptor blockers. The number of patients who were given hydroxychloroquine (HCQ), lowmolecular-weight heparin, steroids and antibiotics (ceftriaxone) was 5, 5, 2 and 5, respectively. All patients recovered eventually and were discharged. The mean duration of admission was 10.6 (SD-4.7) days. Repeat polymerase chain reaction assay (PCR) to demonstrate negativity was done in 64 patients, and the mean duration from the first positive swab to the first negative swab was 15.3 (SD-5.5) days. This period was significantly different between the asymptomatic and symptomatic group (16.2 vs. 13.6 days, $p$-value-0.04).

\section{Discussion}

Asymptomatic transmission of COVID-19 was initially described in household contacts of positive patients from China (7-9). The percentage of asymptomatic COVID-19 in positive patients from China ranged from $1.2-11 \%(10-13)$. However, the rate of individuals with asymptomatic COVID-19 depends highly on the testing strategies as asymptomatic individuals are unlikely to report to the hospital. In estimates derived after statistical modelling from individuals evacuated from China or individuals trapped in the Diamond Princess cruise, the proportion of asymptomatic cases ranged from $17.9 \%$ to $30.8 \%$ (Table 7 ) $(3,4)$. In our cohort, 
Table 7. Studies on transmission dynamics of SARS-CoV-2

\begin{tabular}{|c|c|c|c|c|}
\hline S.N & Author Details & Type of study & Population and Sample size & Results \\
\hline 1 & Bai et al., China & Familial cluster & & $\begin{array}{l}5 \text { patients infected from one asymptomatic } \\
\text { patient }\end{array}$ \\
\hline 2 & Zhang et al., China & Familial cluster & & $\begin{array}{l}4 \text { patients infected from one asymptomatic } \\
\text { patient }\end{array}$ \\
\hline 3 & Luo Y et al., China & Familial cluster & & $\begin{array}{l}4 / 5 \text { household contacts of a symptomatic } \\
\text { physician were positive but asymptomatic }\end{array}$ \\
\hline 4 & NCPERE team, China & $\begin{array}{l}\text { Retrospective review } \\
\text { of records }\end{array}$ & $\begin{array}{l}72,314 \text { patients (including positive and } \\
\text { suspected) }\end{array}$ & $1.2 \%$ asymptomatic \\
\hline 5 & Wang et al., China & $\begin{array}{l}\text { Retrospective review } \\
\text { of records }\end{array}$ & 1,012 non-critically ill positive patients & $3 \%$ asymptomatic \\
\hline 6 & Dong et al., China & $\begin{array}{l}\text { Retrospective review } \\
\text { of records }\end{array}$ & 2,135 positive paediatric patients & $4.4 \%$ asymptomatic \\
\hline 7 & Zhu et al., China & Meta-analysis & 3,062 positive patients & $11 \%$ asymptomatic \\
\hline 8 & Nishiura et al., Japan & Statistical modelling & $\begin{array}{l}565 \text { evacuated individuals ( } 9 \text { symptomatic } \\
\text { positives, } 4 \text { asymptomatic positives) }\end{array}$ & Asymptomatic proportion- $31 \%$ \\
\hline 9 & Mizumoto et al., Japan & Statistical modelling & 634 positive in Diamond princess cruise & Asymptomatic proportion- $18 \%$ \\
\hline 10 & $\mathrm{Hu}$ et al., China & Case series & $\begin{array}{l}24 \text { asymptomatic positive patients at } \\
\text { presentation }\end{array}$ & $\begin{array}{l}21 \% \text { eventually developed symptoms } \\
\text { (presymptomatic) }\end{array}$ \\
\hline 11 & Meng et al., China & Case series & $\begin{array}{l}58 \text { asymptomatic positive patients at } \\
\text { presentation }\end{array}$ & $\begin{array}{l}28 \% \text { eventually developed symptoms } \\
\text { (presymptomatic) }\end{array}$ \\
\hline 12 & An et al., China & Case series & 25 asymptomatic patients at presentation & $\begin{array}{l}36 \% \text { eventually developed symptoms } \\
\text { (presymptomatic) }\end{array}$ \\
\hline 13 & Zhou et al., China & Case series & 13 asymptomatic patients at presentation & $\begin{array}{l}23 \% \text { eventually developed symptoms } \\
\text { (presymptomatic) }\end{array}$ \\
\hline 14 & Samsami et al., China & Case series & 8 asymptomatic patients at presentation & $\begin{array}{l}25 \% \text { eventually developed symptoms } \\
\text { (presymptomatic) }\end{array}$ \\
\hline 15 & Kimball et al., USA & Outbreak & 76 exposed patients ( 23 positives) & $\begin{array}{l}56 \% \text { asymptomatic at presentation }(77 \% \text { of } \\
\text { which were presymptomatic) }\end{array}$ \\
\hline 16 & Arons et al., USA & Outbreak & 76 exposed patients (48 positives) & $\begin{array}{l}56 \% \text { asymptomatic at presentation ( } 89 \\
\% \text { of which were presymptomatic) }\end{array}$ \\
\hline
\end{tabular}

because all travellers were screened irrespective of the symptoms and were admitted irrespective of the severity, the percentage of asymptomatic individuals was higher (59\%).

It is pertinent to distinguish individuals who remain asymptomatic throughout and individuals who are asymptomatic at presentation but develop symptoms later (presymptomatic). The proportion of presymptomatic individuals in patients who are asymptomatic at presentation varies from $21-89 \%$ (Table 7) (14-20). In our study, the number of presymptomatic individuals was only three. The ability of an asymptomatic or a presymptomatic individual to transmit infection was initially questioned. Still, it was found in an outbreak from a skilled nursing facility in the USA, that viral load in all three groups (symptomatic, presymptomatic and asymptomatic) were equally high. Of the 24 specimens collected from presymptomatic individuals, 17 specimens were also viable on culture. In another study of 2001 contacts of 157 symptomatic and 146 contacts of 30 asymptomatic cases, infection rates were $6 \%$ and $4 \%$ respectively $(21)$. The difference in infectivity of symptomatic and asymptomatic cases was found to be statistically insignificant by the authors.

The spectrum of symptomatic patients with COVID-19 ranges from mild to severe. In a large report from China, the proportion of mild patients among all symptomatic patients was $81 \%$. The risk factors for severe disease in patients with COVID-19 ranges from cardiovascular disease, diabetes mellitus, hypertension, chronic lung disease and immunosuppressive conditions. In a study, the mean number of comorbidities in patients who died was 2.7 (25). In another study, the mortality rate was significantly higher in those with comorbidities than those without comorbidities (26). Similar to our study, male sex was associated with more severe illness $(27,28)$. Older age has also been associated with severe disease and mortality $(25,29)$. Infection with respiratory viruses (influenza, SARS-CoV-1) has shown to affect pregnant women disproportionately in terms of increased severity and adverse outcomes (30). The data on the effect of this virus on maternal and fetal well-being is still evolving. The percentage of asymptomatic pregnant patients ranges from 23 to $33 \%$, while the percentage of severe pregnant patients ranges from $5 \%$ to $14 \%$ $(31-34)$. In our series, a total of 14 patients in various trimesters of pregnancy were identified. Except for two pregnant patients who had a mild illness, all the other patients were asymptomatic $(86 \%)$. In a casecontrol study by Li et al., maternal complications were higher in pregnant women with suspected/confirmed COVID-19 compared to controls (pregnant women without COVID-19) (Table 8) (35). Like our study, high NLR, thrombocytopenia, transaminitis, raised 
Table 8. Maternal and foetal outcomes of COVID-19 cases

\begin{tabular}{|c|c|c|c|c|}
\hline S.n & Author Details & Type of study & Population and Sample size & Results \\
\hline 1 & Breslin et al., USA & Case series & 43 COVID-19 positive pregnant patients & $\begin{array}{l}33 \% \text { asymptomatic at presentation. } 9 \% \\
\text { severe and } 5 \% \text { critical }\end{array}$ \\
\hline 2 & Ferrazzi et al., Italy & Case series & 42 COVID-19 positive pregnant patients & $37 \%$ required oxygen support $(21)$ \\
\hline 3 & Yang et al. & Review of published cases & 114 COVID-19 positive pregnant women & $\begin{array}{l}5 \% \text { of the patients had severe/critical } \\
\text { illness }\end{array}$ \\
\hline 4 & Yan et al., China & Case series & 116 COVID-19 positive pregnant patients & $\begin{array}{l}23 \% \text { were asymptomatic at presentation, } \\
\text { while } 7 \% \text { had severe symptoms }\end{array}$ \\
\hline 5 & Li et al., China & Case-control study & $\begin{array}{l}\text { Cases- Pregnant women with COVID-19, } \\
\text { Controls- Pregnant patients without } \\
\text { COVID-19 }\end{array}$ & $\begin{array}{l}\text { Maternal complications were higher in } \\
\text { cases }\end{array}$ \\
\hline
\end{tabular}

inflammatory marker, raised troponin and raised d-dimer are associated with poorer outcomes (36-38).

The most common initial symptoms in patients with COVID are fever, cough, myalgia, rhinitis, diarrhoea, loss of smell and taste (26). It is pertinent to note that even though several guidelines include fever as the entry criteria for suspicion, it is present only in 31$46 \%$ of the patients in various studies. Similar results were noted in our research as well $(26,39)$. The smell and taste alterations in COVID are more subjective than objective, thereby explaining the wide range of prevalence (5 to $98 \%$ ) in various studies $(40,41)$. Most patients with mild symptoms at onset recover without any further progression. A fraction of these patients may develop dyspnea. Like our study, the mean duration of dyspnea development ranges from 5-8 days $(42,43)$.

Compared to other studies that report the casefatality in the range of $1-12 \%$, our outcome was excellent despite our restricted use of antivirals (22-24). This could have been because of many reasons. Those patients who were relatively healthy would have decided to travel, and therefore, our cohort may have been healthier at baseline than other hospital cohorts. Since this was the beginning of the pandemic, all patients were tested and were admitted in an institutional setting. This would have led to the inclusion of more asymptomatic patients leading to early identification of worsening and prompt management. Also, because it was the early part of the pandemic, the hospital resources (human resources and beds) were adequate to manage these patients in the best possible manner.

Apart from the limitations associated with the study's retrospective nature, the discharge criteria changed in the middle of the study period. Consequently, time to negativity could not be calculated in all the patients.

The possibility of transmission from asymptomatic cases which form a significant proportion of total positive patients but are missed on symptom-based screening calls for adherence to preventive measures such as physical distancing, frequent handwashing, wearing of masks in the community and universal masking. Since patients with asymptomatic and mild illness have excellent outcomes without any therapeutic interventions, unnecessary and unproven medications should be avoided in such patients. These patients can also be managed in-home isolation (with monitoring) to decrease the burden on tertiary care hospitals.

\section{Acknowledgements}

Authors gratefully acknowledge the Department of Health and Family Welfare, Udupi District, Government of Karnataka for granting permission to undertake the study.

\section{Funding: None.}

Conflict of Interest: The authors have no conflicts of interest to disclose.

\section{References}

1. Gandhi M, Yokoe DS, Havlir DV. Asymptomatic transmission, the achilles' heel of current strategies to control covid-19. N Engl J Med. 2020; 382:2158-2160.

2. $\mathrm{Wu} Z$, McGoogan JM. Characteristics of and important lessons from the coronavirus disease 2019 (COVID-19) outbreak in China: Summary of a report of 72,314 cases from the Chinese center for disease control and prevention. JAMA. 2020; 323:1239-1242.

3. Nishiura H, Kobayashi T, Miyama T, Suzuki A, Jung SM, Hayashi K, Kinoshita R, Yang Y, Yuan B, Akhmetzhanov AR, Linton NM. Estimation of the asymptomatic ratio of novel coronavirus infections (COVID-19). Int J Infect Dis. 2020; 94:154-155.

4. Mizumoto K, Kagaya K, Zarebski A, Chowell G. Estimating the asymptomatic proportion of coronavirus disease 2019 (COVID-19) cases on board the Diamond Princess cruise ship, Yokohama, Japan, 2020. Euro Surveill. 2020; 25:2000180.

5. Liang W, Liang H, Ou L, et al. Development and validation of a clinical risk score to predict the occurrence of critical illness in hospitalized patients with COVID-19. JAMA Intern Med. 2020; 180:1081-1089.

6. Kumar R, Gupta N, Kodan P, Mittal A, Soneja M, Wig N. Battling COVID-19: Using old weapons for a new enemy. Trop Dis Travel Med Vaccines. 2020; 6:6.

7. Bai Y, Yao L, Wei T, Tian F, Jin DY, Chen L, Wang M. Presumed asymptomatic Ccarrier transmission of COVID-19. JAMA. 2020; 323:1406-1407.

8. Zhang J, Tian S, Lou J, Chen Y. Familial cluster of COVID-19 infection from an asymptomatic. Crit Care. 
2020; 24:119.

9. Luo Y, Trevathan E, Qian Z, Li Y, Li J, Xiao W, Tu N, Zeng Z, Mo P, Xiong Y, Ye G. Asymptomatic SARS$\mathrm{CoV}-2$ infection in household contacts of a healthcare provider, Wuhan, China. Emerg Infect Dis. 2020; 26:19301933.

10. Epidemiology Working Group for NCIP Epidemic Response, Chinese Center for Disease Control and Prevention. The epidemiological characteristics of an outbreak of 2019 novel coronavirus diseases (COVID-19) in China. Zhonghua Liu Xing Bing Xue Za Zhi. 2020; 41:145-151.

11. Wang X, Fang J, Zhu Y, Chen L, Ding F, Zhou R, Ge L, Wang F, Chen Q, Zhang Y, Zhao Q. Clinical characteristics of non-critically ill patients with novel coronavirus infection (COVID-19) in a Fangcang Hospital. Clin Microbiol Infect. 2020; 26:1063-1068.

12. Dong $\mathrm{Y}$, Mo X, Hu Y, Qi X, Jiang F, Jiang Z, Tong S. Epidemiology of COVID-19 among children in China. Pediatrics. 2020; 145 :e20200702.

13. Zhu J, Ji P, Pang J, Zhong Z, Li H, He C, Zhang J, Zhao C. Clinical characteristics of 3,062 COVID-19 patients: A meta-analysis. J Med Virol. 2020; 92:1902-1914.

14. Hu Z, Song C, Xu C, Jin G, Chen Y, Xu X, Ma H, Chen W, Lin Y, Zheng Y, Wang J, Hu Z, Yi Y, Shen H. Clinical characteristics of 24 asymptomatic infections with COVID-19 screened among close contacts in Nanjing, China. Sci China Life Sci. 2020; 63:706-711.

15. Meng H, Xiong R, He R, Lin W, Hao B, Zhang L, Lu Z, Shen X, Fan T, Jiang W, Yang W, Li T, Chen J, Geng Q. $\mathrm{CT}$ imaging and clinical course of asymptomatic cases with COVID-19 pneumonia at admission in Wuhan, China. J Infect. 2020; 81:e33-e39.

16. An P, Song P, Wang Y, Liu B. Asymptomatic patients with novel coronavirus disease (COVID-19). Balkan Med J. 2020; 37:229-230.

17. Zhou X, Li Y, Li T, Zhang W. Follow-up of asymptomatic patients with SARS-CoV-2 infection. Clin Microbiol Infect. 2020; 26:957-959.

18. Samsami M, Zebarjadi Bagherpour J, Nematihonar B, Tahmasbi H. COVID-19 pneumonia in asymptomatic trauma patients; Report of 8 Cases. Arch Acad Emerg Med. 2020; 8:e46.

19. Kimball A, Hatfield, KM, Arons M, et al. Asymptomatic and presymptomatic SARS-CoV-2 infections in residents of a long-term care skilled nursing facility-King County, Washington, March 2020. MMWR Morb Mortal Wkly Rep. 2020; 69:377-381.

20. Arons MM, Hatfield KM, Reddy SC, et al. Presymptomatic SARS-CoV-2 infections and transmission in a skilled nursing facility. N Engl J Med. 2020; 382:2081-2090.

21. He D, Zhao S, Lin Q, Zhuang Z, Cao P, Wang MH, Yang L. The relative transmissibility of asymptomatic COVID-19 infections among close contacts. Int J Infect Dis. 2020; 94:145-147.

22. Verity R, Okell LC, Dorigatti I, et al. Estimates of the severity of coronavirus disease 2019: A model-based analysis. Lancet Infect Dis. 2020; 20:669-677.

23. Zhou F, Yu T, Du R, et al. Clinical course and risk factors for mortality of adult inpatients with COVID-19 in Wuhan, China: A retrospective cohort study. Lancet. 2020; 395:1054-1062.

24. Grasselli G, Pesenti A, Cecconi M. Critical care utilization for the COVID-19 outbreak in Lombardy, Italy: Early experience and forecast during an emergency response. JAMA. 2020; 323:1545-1546.

25. Onder G, Rezza G, Brusaferro S. Case-fatality rate and characteristics of patients dying in relation to COVID-19 in Italy. JAMA. 2020; 323:1775-1776.

26. Stokes EK, Zambrano LD, Anderson KN, Marder EP, Raz KM, Felix SE, Tie Y, Fullerton KE. Coronavirus disease 2019 case surveillance-United States, the 22nd of Januarythe 30th of May, 2020. MMWR Morb Mortal Wkly Rep. 2020; 69:759-765.

27. Chen $\mathrm{T}, \mathrm{Wu} \mathrm{D}$, Chen $\mathrm{H}$, et al. Clinical characteristics of 113 deceased patients with coronavirus disease 2019: Retrospective study. BMJ. 2020; 368:m1091.

28. Kragholm K, Andersen MP, Gerds TA, Butt JH, Østergaard L, Polcwiartek C, Phelps M, Andersson C, Gislason GH, Torp-Pedersen C, Køber L. Association between male sex and outcomes of Coronavirus Disease 2019 (Covid-19)-a Danish nationwide, register-based study. Clin Infect Dis. 2020; ciaa924.

29. Williamson EJ, Walker AJ, Bhaskaran K, et al. Factors associated with COVID-19-related death using OpenSAFELY. Nature. 2020; 584:430-436.

30. Lam CM, Wong SF, Leung TN, Chow KM, Yu WC, Wong TY, Lai ST, Ho LC. A case-controlled study comparing clinical course and outcomes of pregnant and nonpregnant women with severe acute respiratory syndrome. BJOG. 2004; 111:771-774.

31. Hirshberg JS, Stout MJ, Raghuraman N. Coronavirus disease 2019 infection among asymptomatic and symptomatic pregnant women: Two weeks of confirmed presentations to an affiliated pair of New York City hospitals. Am J Obstet Gynecol MFM. 2020; 2:100162.

32. Ferrazzi E, Frigerio L, Savasi V, et al. Vaginal delivery in SARS-CoV-2-infected pregnant women in Northern Italy: A retrospective analysis. BJOG. 2020; 127:1116-1121.

33. Yang Z, Wang M, Zhu Z, Liu Y. Coronavirus disease 2019 (COVID-19) and pregnancy: A systematic review. J Matern Fetal Neonatal Med. 2020; 1-4.

34. Yan J, Guo J, Fan C, et al. Coronavirus disease 2019 in pregnant women: A report based on 116 cases. Am J Obstet Gynecol. 2020; 223:111.e1-111.e14.

35. Li N, Han L, Peng M, Lv Y, Ouyang Y, Liu K, Yue L, Li Q, Sun G, Chen L, Yang L. Maternal and neonatal outcomes of pregnant women with coronavirus disease 2019 (COVID-19) pneumonia: A case-control study. Clin Infect Dis. 2020; 71:2035-2041.

36. Wu C, Chen X, Cai Y, et al. Risk factors associated with acute respiratory distress syndrome and death in patients with coronavirus disease 2019 pneumonia in Wuhan, China. JAMA Intern Med. 2020; 180:934-943.

37. Shi S, Qin M, Shen B, Cai Y, Liu T, Yang F, Gong W, Liu X, Liang J, Zhao Q, Huang H, Yang B, Huang C. Association of cardiac injury with mortality in hospitalized patients with COVID-19 in Wuhan, China. JAMA Cardiol. 2020; 5:802-810.

38. Liao D, Zhou F, Luo L, Xu M, Wang H, Xia J, Gao Y, Cai L, Wang Z, Yin P, Wang Y, Tang L, Deng J, Mei H, $\mathrm{Hu} \mathrm{Y}$. Haematological characteristics and risk factors in the classification and prognosis evaluation of COVID-19: A retrospective cohort study. Lancet Haematol. 2020; 7:e671-e678.

39. Richardson S, Hirsch JS, Narasimhan M, et al. Presenting characteristics, comorbidities, and outcomes among 5,700 patients hospitalized with COVID-19 in the New York city area. JAMA. 2020; 323:2052-2059. 
40. Tong JY, Wong A, Zhu D, Fastenberg JH, Tham T. The prevalence of olfactory and gustatory dysfunction in COVID-19 patients: A systematic review and metaanalysis. Otolaryngol Head Neck Surg. 2020; 163:3-11.

41. Lechien JR, Chiesa-Estomba CM, Hans S, Barillari MR, Jouffe L, Saussez S. Loss of smell and taste in 2013 European patients with mild to moderate COVID-19. Ann Intern Med. 2020; 173:672-675.

42. Huang C, Wang Y, Li X, et al. Clinical features of patients infected with 2019 novel coronavirus in Wuhan, China. Lancet. 2020; 395:497-506.

43. Wang D, Hu B, Hu C, Zhu F, Liu X, Zhang J, Wang B, Xiang H, Cheng Z, Xiong Y, Zhao Y, Li Y, Wang X, Peng Z. Clinical characteristics of 138 hospitalized patients with
2019 novel coronavirus-infected pneumonia in Wuhan, China. JAMA. 2020; 323:1061-1069.

Received August 10, 2020; Revised February 9, 2021; Accepted February 26, 2021.

\section{*Address correspondence to:}

Kavitha Saravu, Department of Infectious Diseases, Kasturba Medical College, Manipal Academy of Higher Education, Manipal, Karnataka, India.

E-mail: kavithasaravu@gmail.com

Released online in J-STAGE as advance publication February 28, 2021. 